\title{
'Bushfalling': the ambiguities of role identities experienced by self- sponsored Cameroonian students in Flanders (Belgium)
}

\author{
Presca E. Wanki ${ }^{\mathrm{a} *}$ and Ine Lietaert ${ }^{\mathrm{b}} \quad 1$ \\ ${ }^{a}$ Doctoral student in the department of Social work and Social Pedagogy, University of Ghent, \\ Belgium \\ ${ }^{b}$ Post-doctoral researcher. Centre for the Social Study of Migration and Refugees (CESSMIR), \\ Ghent University. \\ Department of Social work and Social Pedagogy, University of Ghent, Belgium.
}

Acknowledgement: The authors thank the anonymous referees and Editors who provided very helpful and supportive comments on previous drafts of this paper.

\footnotetext{
${ }^{1}$ a. Presca E. Wanki

Email: nikipris@yahoo.com; presca.essehwankikang@Ugent.be

b. Ine Lietaert

Email: Ine.Lietaert@Ugent.be
} 


\title{
'Bushfalling': the ambiguities of role identities experienced by self- sponsored Cameroonian students in Flanders (Belgium)
}

\begin{abstract}
Educational mobility in Cameroon is not a recent phenomenon, yet through the notion of 'bushfalling' - that is, the way international migration is envisioned and constructed in Cameroon - young Cameroonians explore routes to new destination countries for educational migration as a way of fulfilling their dreams of a better future. These dreams are enabled and challenged by the different role identities the students have to combine in the destination country. The current article focuses on self-sponsored Anglophone Cameroonian students in Flanders, who combine roles as students, workers and transnational caregivers. Using bushfalling as our analytical lens, we explore the change in understanding bushfalling through the educational route and its implications on transnational family relations. Further, we explore the various ways in which these students negotiate and manipulate the different roles, yet keep the student role identity in the centre, and how this in turn informs their next step in the education-migration trajectory.
\end{abstract}

Keywords: bushfalling, international educational mobility, role identity, student-worker, caregiver, Flanders, Cameroon 


\section{Introduction}

Scholars have witnessed a strong growth in educational migration throughout the world in recent decades (Olwig and Valentin 2015). While traveling for education was for a long time a privilege of elite groups, and international student migration from countries in the South was primarily structured by preceding colonial ties, contemporary educational migration has widened (Olwig and Valentin 2015). It has become accessible to more people, geographic routes have become more diverse and 'new categories' of international students have emerged in various Western countries (Valentin 2015). As a result, the number of foreign tertiary students in OECD countries has grown annually from 2000 to 2012, reaching 4.5 million students seeking education outside their country of origin (OECD 2014). Although the heterogeneity within the group commonly identified as 'international students' is an apparent reality, the wider body of literature on international students still mainly approaches them as being a young, well-resourced and elite group for whom educational migration is a vehicle for self-cultivation and transformation (Amit 2010; Robertson 2011). In this way, the varying historical and personal circumstances under which educational migration occurs are disregarded. Consequently, as we argue in the current article, far too little attention is paid to the experiences and outcomes of the education-migration nexus for self-sponsored students who are not mere 'students', but combine various role identities in their daily lives (Olwig and Valentin 2015; Robertson 2011).

Various migration scholars have already brought about an important change by studying the engagement of international students in the labour market (King and Raghuram 2013; Neilson 2009; Olwig and Valentin 2015; Raghuram, 2013; Robertson 2011). These studies reveal that many international students aim for social mobility 
through the educational route. They engage in employment to pay for their migration and education, and to support themselves and their families who may have contributed financially. This also illustrates the issues of transnational engagement and the influence of kinship ties that are at play for many people migrating to Western countries (Fleisher 2007; Olwig and Valentin 2015). These studies emphasise the importance of recognizing the students as 'complex individuals who are entangled in a wide set of relations [...] they are simultaneously family members, workers and students' (King and Raghuram 2013, 131; Leung 2017; Genova 2016; Pham and Saltmarsh 2013). We argue that as part of these relations, the students possess different role identities, referring to "parts of a self, composed of the meanings that persons attach to the multiple roles they typically play in highly differentiated contemporary societies' (Stryker and Burke 2000, 284). Such identities are dynamic, fluid and context specific (Genova 2016; Olwig and Valentin 2015). As with any social identity, this is always relational, which means that it can be both self-ascribed and ascribed by others (Olwig and Valentin 2015). With regard to the latter, much research indeed illustrates that international students' position between work and migration (Wilken and Dahlberg 2017) creates ongoing debates in destination countries, in which international students have continuously been under scrutiny concerning whether they can be considered as 'proper' students (Raghuram 2013; Olwig and Valentin 2015). Hence, these students are confronted with a 'complex field of contradictory expectations and demands' created by the various role identities, which influences their daily lives and might restrict the aims that have been set out through migration (Olwig and Valentin 2015). In this respect, identities form the backbone of making sense of the experiences of international students (Easthope 2009).

While various researchers recognize international students' role as a family member, little attention has been paid to their transnational caregiving role, and in 
particular its intertwining with their roles as a student and as a worker. However, as we show in our focus on self-sponsored Anglophone Cameroonian students in Flanders (Belgium), it is a pivotal identity role for these self-sponsored international students, and crucial to understanding the way they manipulate different role identities in order to succeed academically.

The first aim of this paper is to enrich the literature on international student migration by critically exploring the "multiplicity and hybrid figure of the studentworker' (King and Raghuram 2013, 134) who might also occupy positions including husband, mother, wife, and/or caregiver to family members at home. We argue that selfsponsored students are an interesting case to examine, as they have to support their own studies, which might intensify the connection between being a worker and a student. Moreover, since their resources are limited, their family often contributes substantially to finance their trip abroad (Olwig and Valentin 2015), which might in turn strengthen their obligations as migrants and transnational caregivers. Being part of these relations, they therefore possess three main role identities (student, worker and transnational caregiver), needing to fulfil the expectations that come with each of them, as well as manipulating all the roles in their everyday life (Stryker and Burke 2000). Further, since the temporariness of the student identity has received far too little attention to date (Olwig and Valentin 2015), this article explores how the conflicting role identities possessed and experienced by self-sponsored Cameroonian students inform the next step in their mobility patterns after completion of their master's degree.

We approach the topic by using the concept of 'bushfalling' as an analytical lens (Alpes 2014; Nyamnjoh 2011; Pelican 2013). This term is a metaphor widely used in Anglophone Cameroon to refer to international migration, and comprises a fundamental part of Cameroonian culture and society. It refers to 'greener pastures' through migration, 
and the determination and strength it takes to gain wealth in order to be considered as 'successful bushfallers'. This cultural understanding of migration links migration to an increase in social status. Not only does this apply to the students, but having a family member in the 'bush' (i.e., abroad) automatically confers social status to the family at home (Valentin 2015; Alpes 2014). This shows the central and reciprocal nature of the concept. As we will show, the particular understandings of international migration as bushfalling clearly imbue a complex web of expectations and obligations for those people going to the bush (Nyamnjoh 2011). Student migration is not only seen as 'studying abroad', but is also regarded as a form of bushfalling that creates a different reality for self-sponsored Cameroonian students. In the subsequent paragraphs, we demonstrate the 'slipperiness' of the concept of bushfalling, which involves different and sometimes contradictory understandings of what it means and how it is performed.

We suggest that it is therefore an essential framework within which to understand the ways in which self-sponsored Anglophone Cameroonian students in Flanders manipulate and negotiate their multiple role identities. It should also be noted that bushfallers who have left after the 1990s through the educational route are denounced for being more pragmatic, and also for prioritizing financial rewards above educational goals (Nyamnjoh 2011), while the meaning, outcome and limits of juggling these roles have not been addressed. Therefore, as a second aim this article sets out to broaden understandings of bushfalling by exploring its educational route. Since 'success' has local meanings in the context of Cameroon, we explore how educational goals relate to the need to be 'successful' in the 'bush' and the implications for transnational family relations.

In what follows, we first explore the context of this case study to understand the contemporary mobility patterns of students from Cameroon, and clarify the conditions 
for international students in Flanders. We then present the concept of bushfalling, which in the subsequent section, will be used as an analytical lens to unveil how the three role identities are negotiated and how this forms the next step in the migration trajectory.

\section{Understanding educational migration}

\section{From Cameroon...}

As in many parts of Africa, mobility is not new in Cameroon. The country has a long history of mobility both within and across its national borders (Pelican 2013). Its colonial past shows that Cameroon was first administered by the Germans (1884-1918). In 1919, it was divided and placed under the mandate of the French and the British. The larger part went to the French, and the Western region was under British rule. In 1960, Cameroon became independent and the two regions were integrated into a single country with coexisting French and English administrative systems. This triple colonial history with Germany, France and the United Kingdom has structured the country's migration patterns for decades. During the colonial era, educational development was specifically the responsibility of the Christian missionaries (Mbaku 2005; Ngalim 2014). Since students did not possess the financial resources for educational mobility, scholarships for training were offered to many young Cameroonians by churches based in the United Kingdom, France and Germany (Mbaku 2005). After independence (1960) and up to the early 1980s, the established colonial ties meant that the preferred destinations for most young Cameroonians remained the United Kingdom, France and Germany.

Today, due to high unemployment rates, corruption and the fact that diplomas from Western universities are considered to be of higher value than those achieved in Cameroon, the desire to migrate is generally high for young Cameroonians, and this is even more the case for young people from the Anglophone region (Alpes 2011; Fleischer 2007). The secession and democratisation process in Cameroon led to the birth of 'the 
Anglophone problem', which refers to the perception in Anglophone Cameroon that they are disadvantaged and devalued by the regime (Alpes 2011). These young Cameroonians, especially university graduates, are confronted with increasing difficulties in finding employment. Thus, Anglophone Cameroonians assess their chances of success as higher far away from Cameroon (Alpes 2011), and educational mobility through bushfalling is seen as a way of fulfilling their dreams of a better future.

The terminology of bushfalling became popular in Cameroon in the 1990s, and refers to "the act of going to the wilderness [i.e., the bush] to hunt down meat [i.e., money] and bring back home the trophies' (Alpes 2011, 2; Nyamnjoh 2011). Nowadays, this equates to travelling overseas and earning money to send back home to the family. The notion of bushfalling entails that a person who migrates to a Western country desires or is expected to return home in order to share the wealth he or she has accumulated (Alpes 2011). As we will illustrate, in bushfalling, remittances are evaluated in terms of reciprocal financial support, emotional support and social status.

As it has become much more difficult to access funds from former colonial governments or missionary bodies in recent years, families have taken up the responsibility to finance the education of their children abroad (Fleisher 2007) leading to more self-sponsored Cameroonian students. This consequently opened up the physical movement of young Cameroonians to other countries, such as Belgium and the United States.

Dreams of bushfalling through education are, however, challenged by the temporal status as 'students', by the restrictions imposed on this entry channel and by the different role-based identities students have to combine while in the destination country; a harsh reality that is seldom visible to young Cameroonians before they migrate (Alpes 2011; Fleischer 2007). The influence of migrants or returnees, who often present 
themselves as having lived an affluent life abroad, pinpoints the role of imagery in (international) migration for envisioning 'green pastures' (Salazar 2011). Indeed, on arrival in Belgium, the imaginings of a stress-free life often do not align with the reality in the host country.

\section{... to Flanders}

The student route was opened as an entry channel in 1980 in Belgium, and became a popular option for third-country nationals in the first decade of the twenty-first century (Caestecker 2012). This led to a considerable increase in the number of international students in Belgian institutes of higher education. In this article, we study the educationmigration nexus for Cameroonian students in a specific region of Belgium, namely Flanders. Educational policy is the competence of the two language communities in Belgium providing higher education (the French and Dutch-speaking communities), and different types of international students are attracted to these regions.

The French-speaking institutions have a global appeal to most international students from Africa, while the Flemish institutions of higher education have had to make an extra effort by providing courses in English to attract a sizable number of international students. In Flanders, these efforts have not only increased the number of international students, but the international student population has also become more diverse. Although Cameroonian students are a relatively new group in Flanders, the percentage of students from Cameroon has been increasing since 2004 (52 students), and their absolute numbers had quadrupled by 2011 (235 students) (Caestecker 2012). For the vicinity of Leuven, where this study was conducted, the number of master's students from Cameroon increased from 41 in 2007, to 74 in 2015. In 2015, only two of these students were scholarship recipients, while 72 were self-sponsored (KU Leuven 2018). 
International students are registered on a full-time basis and are expected to meet the standards set by the university: a success rate of at least 50 per cent for all the course units taken. There is a refusal for enrolment if a course has been failed for a maximum of three academic years (KU Leuven 2017).

In Flanders, the increase in the international student population has also been accompanied by debates on the 'misuse' of the student migration route in terms of students working outside the terms of their visa permission, which is said to correlate with non-attendance of classes and limited or no progress in studies (EMN 2012; Caestecker 2012). In order to ensure compatibility with their studies, students are required to have a Type $\mathrm{C}$ work permit to engage in employment, which allows them to work a maximum of 20 hours per week during the academic year (Caestecker 2012). This control over the number of hours students can work polarizes the boundaries between labour migrants and student migrants, and aims to limit international students to be primarily studying (Raghuram 2013). Turning to the situation of labour migrants in Belgium, reports of discrimination have been on the increase, especially concerning the labour outcomes of immigrants; even those who obtained their education in Belgium (FRA 2017; OECD 2008). This context may contribute to international students or workers feeling as 'the other' (Genova 2016).

\section{Bushfalling as an analytical lens}

Based on the concept of bushfalling and a review of relevant literature, our data collection started from the presumption that all respondents combine the role identities of student, worker and transnational caregiver in varying ways.

Looking at the student role within the concept of bushfalling, we see that education has largely been seen as a gateway into the host country, thereby suggesting that this role is subordinate to the roles of worker and transnational caregiver (Nyamnjoh 
2011). Education through bushfalling also implies that the student status is these people's access to the envisioned brighter future.

Being self-sponsored also implies that these students need to work to pay for their education, and thus that they might have limited funds to finance projects at home. Nevertheless, the work identity actually buttresses the general view of the term bushfalling, which means to 'hunt' and bring the 'game' back home. Thus, the family still associates the bushfaller with expectations of receiving money transfers (Alpes 2014). Having this identity means they will 'hustle' by doing any available (student) jobs so as to meet the needs of their families and friends.

The transnational caregiver role is therefore essentially intertwined with the role of a worker. Like other international migrants, bushfallers are expected to provide emotional support by staying in touch with relatives, mainly through frequent communication, occasional visits to the family (Baldassar 2007) and remittances, especially in times of crisis (Mazzucato 2009). In most cases, transnational caregiving occurs through financial remittances, thereby taking care of the health and education of their family (Fleisher 2007), which makes 'their presence felt' although they are far away. However, the reciprocal nature of transnational caregiving also makes the reverse remittances important to consider (Mazzucato 2011). Family members, for example, can take care of the children of international students, and in this way also enable the bushfallers to take care of the family in return through financial remittances. Moreover, they provide emotional support through frequent phone calls. Therefore, being a bushfaller strongly re-positions people in their families (Dalgas 2015). This changing responsibilities within the family reveals that they are proactive agents, who reconstruct transnational relations in terms of their frequency of sending remittances. 


\section{Methods}

The data for this article was collected through semi-structured interviews with 15 Anglophone Cameroonian self-sponsored students in the summer of 2015 (eight females and seven males), studying in the vicinity of Leuven, which is one of the biggest student cities in Belgium. They were enrolled in their first master's course, studying subjects including anthropology, management, law and food technology. The selected students in this study had an urban background and came from the lower middle class of Cameroonian society. All of them had gained their bachelor's degree in Cameroon in the University of Buea. They did not see themselves as privileged, but stated they used educational migration through bushfalling to acquire social status at home. Also their families associated this particular form of migration with increased social status, especially in terms of future employment in Cameroon or abroad, which would mean that the benefits would trickle down to them in the form of remittances. Three respondents were unmarried, twelve were married, with only one having a spouse in Belgium. Except for the student with a spouse in Belgium, all of their immediate (nuclear and extended) families were in Cameroon. The small sample size did not allow differentiation in experiences based on gender. However, from the perspective of bushfalling, gender seems less relevant than other characteristics, such as being intelligent, mature and selfdependent for being successful 'in bush' (Alpes 2011; Fleisher 2007).

The respondents were selected through the network of the first author, who is a Cameroonian international student herself, and subsequently through snowball sampling. Only self-sponsored students who had been in Belgium for at least one year were selected, since this increased the likeliness that the respondents would be able to assess the dilemmas that come with bearing various role identities and how to manage them. 
The semi-structured interviews were built around key themes centred on the respondents' biographies, their lives in Flanders as students, workers and transnational caregivers, and lastly their next step after the completion of their studies. The interviews were conducted by the first author during home visits, and in some cases added to with Skype interviews for clarification and further completed by field notes of informal interactions between the researcher and the respondents. The position of the first author as a self-sponsored student herself allowed a thorough insight into the struggles that might be present among the respondents, leading to more directed questioning in order to explore these issues in depth. Moreover, the researcher's revelation of personal struggles minimized the inequality inherent in a researcher-subject relationship, and often triggered the respondents to reflect on these issue (Le Espiritu 1994). The analyses of how students juggled, confirmed or questioned the multiple role identities conferred to them as being bushfallers are presented in the following section.

\section{Experiencing life as a bushfaller}

\section{Manipulating three identities as a student, worker and transnational caregiver}

Bella, who was married with a child, labelled the balancing of her different role identities as being a 'shadow student'. According to her:

In fact I have a crazy schedule and sometimes when I think about my life in Europe, I laugh because I am like a 'shadow student' [...] and now that I am a mother, it is even worse because I have someone whose future now depends on me and that's a huge responsibility.

This statement captures the lives of many self-sponsored Cameroonian students in Flanders. We believe that her description of being a 'shadow student' is an interesting metaphor. It illustrates that she, as did all other respondents, mainly identified with her role as a student. Educational goals were central for all these bushfallers, which brings 
into question the premise that education is only used as a gateway into the host country (Nyamnjoh 2011). In a similar vein, other research shows that international students emphasise their status as 'students' so as to differentiate themselves from other categories of migrants, such as refugees and migrant workers. This is in an attempt to combat the negative stereotypes associated with them, such as 'foreigner' or 'alien' (Valentin 2015; Bilecen 2013). In this respect, there is an interplay of class and status among migrants. International students engage with 'othering' other migrants as unskilled manual labourers and thus perceiving themselves to be legitimately higher in status and class because of their level of education, illustrating that 'class' is self-ascribed and subjectively experienced (Valentin 2015).

Bella's wording, and several examples of others, nevertheless show how the student identity is often overshadowed by other role-based identities. When the respondents were expected to contribute to group assignments, for example, they communicated with other students (who most often were not student workers) by email, since group work was often arranged during their 'working hours'. In this way, they participated virtually, which aligns with the findings of Wilken and Dahlberg (2017) that the incompatibility of students' schedules often leads to them becoming invisible or detached from the student environment at the university and resonates with the expression of being a 'shadow' student.

However, this framing as a shadow student does not do justice to the way the respondents also actively and creatively negotiated the different roles and made specific choices depending on the circumstances, their personal goals and their obligations. Different respondents explained that when faced with conflicts, they weighed up the options of either attending lectures or going to work. They chose to miss lectures, especially when they were newly employed or in situations when they needed the money 
to maintain themselves or their family. By contrast, at times when class attendance and participation were a prerequisite for the course or exams were approaching, students often left work to go to classes, to ensure they succeeded academically. As Ruth explained,

Exam periods are always rush hours for me and to ensure I have good grades, I often take a complete break from work so as to concentrate during exams. I even go to the library and I study for very long hours since I do not work during that period.

The combination of work and studies is of course not exclusive to international students. There is an extensive body of literature reporting on the negative effects work has on students' academic performance, since they experience a higher level of stress, miss lectures, have less time to study and face time-management issues (Winn 2002; Broadbridge and Swanson 2005, 2006; Moreau and Leathwood 2006). Despite the commonalities between local and international students in combining work and studies, for international students - as we show in the next paragraph - it is their migrant identity combined with transnational obligations that seems to give an additional nuance and sometimes adds to the conflicts they experience, putting the 'student identity' under extra pressure.

Inherent to the concept of bushfalling, the students are signatories to a form of unwritten contract, involving transnational obligations and responsibilities regarding remittances to families and friends who may have helped to finance the stay abroad (Fleisher 2007). Therefore, their transnational lives create the experience of a 'double engagement' (Grillo and Mazzucato 2008) between their life as students and workers in Belgium, and their families in Cameroon. As illustrated above, the (financial) demands of relatives at home influence the balance between work and study, and the respondents were compelled to 'take actions, make decisions and develop subjectivities and identities' 
depending on their transnational network of relationships (Pham and Saltmarsh 2013, 132). It is crucial to note that given their temporal status as students, families often understood that they might be unable to provide consistently. Therefore, financial remittances for major projects could be postponed in the long run, but the family benefits from the social prestige of having an educated person in the family (Olwig and Valentin 2015, 253). However, one of the respondents explained that this additional role as a caregiver resulted in him putting his own education 'in the shade' by prioritising that of his siblings (Fleisher 2007). According to Che, whose spouse and family were in Cameroon:

Since I am here to study, I prioritize the education of my siblings' health and daily subsistence. I can't really determine the amount I send monthly, because there are times when I can send money for up to three times a month, especially when health issues are concerned. I send it when the need arises because I can't be here eating well not knowing how my family is.

However, taking care of the wellbeing of his siblings also gave Che a certain satisfaction, thus it affected his wellbeing. This mutual influence of wellbeing might be even stronger for students who have a spouse and children in Cameroon, whereby constant communication and financial provision are essential. As explained by Xavier,

Today, I called my family four times and there is no schedule for that, because being far away from them is so emotional. Even though I am far off, I still occupy my position as a father and husband. When there are issues in the family, I call and resolve them from here.

The respondents did not feel 'forced', but instead felt the obligation to 'give back', which further pinpoints the extent to which the notion of bushfalling is engrained in the Cameroonian culture and society (Fleischer 2007). Although juggling the multiple role identities is sometimes seen as overwhelming, it therefore also creates an 'inner peace' 
when the students are able to meet their educational goals as well as taking care of the wellbeing of their families. In the words of Olwig and Valentin $(2015,254)$, 'migration for educational purposes therefore involves continuous shifts in social positioning and the negotiation of several social identities that, at times, can be experienced as conflicting, but also as liberating'.

Moreover, in some cases this combination of roles might also be to the benefit of the students, since they are able to put some identities 'on hold' for a while in order to focus on one particular identity at a specific time. According to Beatrice, who had all of her family in Cameroon,

\begin{abstract}
Although I care a lot for my family, this was also draining me physically and emotionally. So, I have decided not to call or send money for some time so that I can focus on myself. After doing this for a while, I feel so relieved, knowing that I would not call or receive any call regarding some crisis at home.
\end{abstract}

The ability to reduce communication on a short-term basis with their families is made possible by distance, which 'has the effect of filtering out but the most urgent requests' (Whitehouse 2011, 103) and allows being physically away from everyday problems and the needs of one's family (Prothmann 2017).

Lastly, we point out that in looking for the ways in which the respondents managed their triple role identities, it became clear that other roles also coincided with these central role identities. Several respondents belonged to Cameroonian cultural associations led by students, which seek to enhance the cultural identity of their members and foster development in Cameroon through charity donations. Hence, in a similar vein as has been described for diaspora communities (Robertson, 2011), they identified as 'development agents', as they formulated and realised community projects aimed at the education of underprivileged children. These cultural associations were also actively engaged in 
orientating newcomers to Belgium about the life and culture in the country, and most of all, the importance of learning the language as a way of integrating and securing a decent job. Further research should explore how these identities, and possible other identities, interact with the student, worker and caregiver role identities as already explained above.

\section{Juggling and prioritising, yet retaining all role identities}

The stories above already hint at the strong interconnection between the three role identities. It appears that all three are essential in the realisation of bushfalling through education, and therefore managing them will be a source of additional pride for the family and of accomplishment for the student. The stories of the students mainly reveal this essential intertwining when they talked about the grave consequences if they were unable to connect and reconcile all the identities.

As a first example of this, Nathan explained that although he often prioritized job offers over attending classes, the earnings from 20 hours of work were not enough to cover his responsibilities at home. The limit on the number of hours students can work, as well as the standards set by the university, can be said to be 'part of the strategy for managing student migration and disciplining students' (Raghuram 2013, 149) and sometimes obstructed the respondents from fully committing to all their roles.

Second, not being able to manage the three role identities could foreclose their stay in Belgium and their career aspirations. All the respondents were aware of the repercussions of ignoring their student identity, which thus justifies their emphasis on the importance of meeting the 'standards of the university'. Ruth, quoted above, continued by reiterating that;

I do not work during that period [exams]. If I don't do this, I'll be a 'sans papier' in this country and I can't afford that now because all my dreams of having a decent job would have gone down the drain. 
Being 'sans papier' comes with perils that ultimately affect the wellbeing of the students and of their families. As a means of avoiding this, the student identity becomes central and the work and caregiver roles are deliberately put 'in the shade'. Moreover, this quote of Ruth and her referral to dreaming of 'a decent job' is again a striking illustration of how the context in the host country largely determined the abilities of the respondents to combine the triple role identities and highlights an extra dimension in their situation compared with local student workers. As international students, the respondents were overrepresented in low-skilled jobs due to the different forms of discrimination they experienced in the job market. Roy explained:

It's just funny how sometimes you are treated like a nobody. Applying for a job is one thing, and getting it is another. I once applied to a company which recruits in all sectors [including skilled sectors] and within the academic year, there was no response from them. They waited until the beginning of summer and contacted me if I can work in the farm, implying that this is the nature of job preferred for 'my kind'.

This form of discrimination experienced by Roy and others strongly questions the generalisability of the assertion made about local student workers that combining two roles is beneficial to student-workers, since the skills obtained from work can be transferred to future occupations (Lucas and Lammont 1998). Such discrimination is common among many international students (Wilken and Dahlberg 2017), which reveals the continuous influence of race and ethnicity, in terms of their vulnerability through obtaining lower skilled and lower paid student jobs and leading to a high level of skill waste among (student) migrants (Leung 2017). Although such jobs enable the financial remittances needed to live up to the notion of bushfalling, the low social status and waste of skills that accompany it clearly contradict the students' aims to gain social status through the educational route. 
Some research argues that the distance from relatives at home allows migrants to take any type of job abroad 'without the danger of tainting the status of young men and their kinship' (Prothmann 2017, 7). However, as many of the respondents came to Belgium to improve their human capital, skills and social status, they were often extremely frustrated by the fact they felt restricted to low-skilled jobs. The nature of the work they were engaged in was described by the respondents as being a 'brain waste', and physically and mentally exhausting. Hence, obtaining their master's degree - thus holding on to their student identity - could be a way out of this. Due to the lived experiences of these students, they nevertheless felt as 'the other' or 'out of place' in Belgium. Another solution to reconcile these conflicts was to leave Belgium, an issue that will be further discussed in the next section.

In sum, with the analysis above we show that the student role identity was clearly prioritized for various reasons. However, these students were also committed to all the identities because they are linked and there can be a negative effect if one is neglected. The multiple role identities of these students thus reinforce one another, implying that they involve large and roughly equivalent commitment and salience (Stryker and Burke 2000).

\section{Next step in the education migration nexus}

Although involving many challenges, educational migration enabled these self-sponsored Cameroonian students to finance their studies and take care of their families at home. This leads to the central, yet often overlooked questions: What if the central role of the student comes to an end? And, how does this relate to being successful 'in bush'? The main idea of bushfalling is to return home after studies, so as to contribute to development. However, as a result of the economic crisis in the 1980s, the option of 
students to return was discouraged through the increased demand for remittances (Nyamnjoh 2011, 704). Further, the notion of bushfalling places emphasis on increased social status, therefore if a student decides to return home temporarily or permanently, he or she will have to live up to the status of a bushfaller. To return home as a bushfaller thus requires preparation to live up to the expectations of family and friends. This put pressure on the respondents. They had a fear of returning as 'unsuccessful' and also returning to a jobless future, avoiding which was their main motivation for leaving the country.

At the time of the interviews, the self-sponsored Cameroonians had different feelings regarding the next steps after completion of their studies. There were students who had concrete plans regarding relocating to English-speaking countries such as the United States and Canada, applying for the skilled immigration programmes into Denmark (this programme ended in 2016) or moving to Germany. These students searched for countries with favourable integration policies, and this information was acquired through network of friends located in such countries. Clement explained:

I do not want to continue doing domestic cleaning, so I'd prefer to relocate to an English-speaking country because of its good social system, job opportunities in my field of specialization as well as no language barriers.

Another group of students who had no plans or were still unsure about their next step enrolled in Dutch language classes so as to become integrated in Belgium. Lastly, a few students were considering the option of returning home. This was largely influenced by the desire to reunite with their spouse, which illustrates how biographical circumstances shape migration choices (Olwig and Valentin 2015).

From the narrative of Clement, students can be seen as just 'passing through' from their host countries to countries with policies favouring immigrants, which also strengthens the metaphor of being 'shadow students'. In this regard, Chelpi-Den Hamer 
and Mazzucato (2009) argue that if it is too difficult to get a visa extension or to convert a student visa into a work permit, international students prefer to move to an alternative destination that seems more 'flexible' and offers better opportunities (Findlay et al. 2012). This may explain why some of the respondents at the time of the fieldwork were considering the skilled application programmes into Denmark and Canada. In this case, the respondents considered the transferability of human capital was possible in other countries, but not Belgium. This relocation seemed largely driven by their desire to fulfil their dreams through the opportunities (based on their academic qualifications) that these countries offer (Robertson 2011). In line with Wilken and Dahlberg (2017), most students' feeling of 'invisibility', combined with a sense of a lack of opportunity, made them doubt the purpose of being in Belgium.

Thus, in accordance with the findings of the Migration Policy Group (2012), this study also confirms that the key factors determining whether students stay on after graduation include the legal framework governing their stay as well as their ability to obtain post-study employment and residence. More so, the aforementioned report further clarifies the fact that policies and laws governing the stay of international students after completion of their studies fits the overarching needs-based approach, whereby international students can only be allowed into the labour market if there are no qualified EU nationals. 


\section{Conclusion}

This article examines the triple role identities faced by self-sponsored Cameroonian students, as full-time students, workers and transnational caregivers. Based on the results of this study, two main concluding remarks can be made.

First and foremost, on the one hand, the migration of students has been greatly promoted through the internationalization of education (Amit 2010), an evolution that also attracts students from less privileged backgrounds who see education as a means to achieve upward social mobility. However, in the case of this study, the current political and economic context in Cameroon as well as increased restrictions on international (student) mobility, compels these students to combine the roles of student, worker and caregiver to attain this dream of educational achievement; and consequently, upward social mobility. On the other hand, although literature about international students, and about mobility in general, often recognizes and sometimes even celebrates the fluidity of identities as an inherent feature of the current global world, it seems that such fluidity is not tolerated for everyone (Glick Schiller and Salazar 2013). We have indicated that it is precisely the combination of different roles that puts these students 'under suspicion' in policy discourse and general perceptions both 'at home' and 'abroad'. Moreover these self-sponsored international students are increasingly confronted with structural constrains obstructing their possibilities to successfully combines these roles, with discrimination on the labour market based on ethnicity, both as student as well as upon graduation, as striking example. We argue that this is portrayed in the shifts that have occurred over the years in the ways international students are perceived in policy discourses. From being previously seen as 'desirable' migrants whose capital would be important as consumers of education and their labour as future workers, they are nowadays seen as 'opportunistic backdoor migrants' for whom any shifting between, or 
combining of, the categories of student, worker or migrants is restricted as much as possible (Robertson 2011). This leaves these self-sponsored Cameroonian students in a paradoxical situation, which seems to hinder the realisation of their migration goals and influence their future career aspirations.

Second, the analyses show how the concept of bushfalling, and thus a sociocultural understanding of mobility, is critical to increase insights into the experiences and outcomes of international student migration. Through the notion of bushfalling, these Cameroonian students were by default also workers responsible for the wellbeing of their family, which strongly shaped their lived experience and their future mobility patterns. This makes it clear that it is not only the previously-mentioned structural conditions that urge students to engage with multiple role identities. In the case of student migration from Cameroon, the socio-cultural context also does, and defines what students are, and when they are successful international migrants. Clearly, the results show how these multiple role identities can be conflicting, yet also how they are creatively negotiated. Therefore, through the manipulation of their role identities and by putting the student identity in the centre, these students essentially redefine the notion of success ingrained in the concept of bushfalling. They reveal that the desire for both education and migration options often go hand in hand and their goal of increasing human capital is not merely a gateway into the host country with financial rewards being the main objective. More so, their ability to combine the three roles, achieving their educational goals as well as working to take care of their wellbeing and that of their families, is a 'hustle on its own' and regarded as 'being 'successful. This combination of three role identities is heightened by their temporal status as students, which had some implications on transnational family relations in terms of the level of support they were able to provide. Yet in combining these different roles 
and making choices about which role to put to the fore, they actively and strategically reconstruct their responsibilities and transnational relations. 


\section{References}

Alpes, Maybritt Jill. 2011. Bushfalling: How young Cameroonians dare to migrate. Amsterdam: Amsterdam, Institute for Social Science Research.

Alpes, Maybritt Jill. 2014. "Imagining a future in 'bush': migration aspirations at times of crisis in Anglophone Cameroon." Identities 21 (3): 259-274. doi:10.1080/1070289X.2013.831350.

Amit, Vared. 2010. "Student Mobility and Internationalisation: Rationales, Rhetoric and Institutional Isomorphism." Anthropology in Action 17(1): 6-18. doi:10.3167/aia.2010.170102.

Baldassar, Loretta. 2007. "Transnational Families and the Provision of Moral and Emotional Support: The Relationship Between Truth and Distance." Identities 14 (4): 385-409. doi:10.1080/10702890701578423.

Bilecen, Başak. 2013. "Negotiating differences: cosmopolitan experiences of international doctoral students." Compare: A Journal of Comparative and International Education 43 (5): 667-688. DOI:10.1080/03057925.2013.821329.

Broadbridge, Adelina, and Vivien Swanson. 2005. "Earning and learning: how termtime employment impacts on students' adjustment to university life." Journal of Education and Work 18 (2): 235-249. doi/abs/10.1080/13639080500086008.

Broadbridge, Adelina, and Vivien Swanson. 2006. "Managing Two Roles." Community, Work \& Family 9 (2): 159-179. DOI:10.1080/13668800600586878.

Caestecker,Frank. 2012. "Migration of International Students to Belgium, 2000-2014." European Migration Network. Accessed August 2017. 
https://emnbelgium.be/publication/migration-international-students-belgium2000-2012-emn.

Chelpi-Den Hamer, Magali, and Valentina Mazzucato. 2009. "The role of support networks in the initial stages of integration: The case of West African newcomers in the Netherlands." International Migration 48 (2): 31-57. doi/10.1111/j.1468-2435.2009.00545.x.

Dalgas, Karina Märcher. 2015. "Becoming independent through au pair migration: selfmaking and social re-positioning among young Filipinas in Denmark." Identities 22 (3): 333-346. doi:10.1080/1070289X.2014.939185.

Easthope, Hazel. 2009. "Fixed identities in a mobile world? The relationship between mobility, place, and identity." Identities 16 (1): 61-82. doi:10.1080/10702890802605810.

EMN. 2012. "Immigration of International Students to the EU." Accessed October 2016. https://emnbelgium.be/publication/immigration-international-students-eueu-synthesis-emn.

Findlay, Allan M., Russell King, Fiona M. Smith, Alistair Geddes, and Ronald Skeldon. 2012. "World Class? An Investigation of Globalisation,Difference and International Student Mobility." Transactions of the Institute of British Geographers 37 (1)): 118-131. DOI: 10.1111/j.1475-5661.2011.00454.x.

Fleischer, Annett. 2007. "Family, Obligations, and Migration: The Role of Kinship in Cameroon." Demographic Research 16 (13): 413-440. doi:10.4054/ DemRes.2007.16.13. 
FRA. 2017. Second European Union Minorities and Discrimination Survey (EU-

MIDISII). European Union Agency for Fundamental Rights (FRA).

http://fra.europa.eu/en/publication/2017/eumidis-ii-main-results

Geddie, Kate. 2013. "The Transnational Ties that Bind. Relationahip Considerations for Graduating International Science and Engineering Research Students." Population, Space and Place 19 (2) : 196-208. DOI: 10.1002/psp.1751.

Genova, Elena. 2016. "To have both roots and wings: nested identities in the case of Bulgarian students in the UK." Identities 23 (4): 392-406. DOI: 10.1080/1070289X.2015.1024125

Glick Schiller, Nina, and Noel B. Salazar. 2013. "Regimes of Mobility Across the Globe." Journal of Ethnic and Migration Studies 183-200. doi:10.1080/1369183X.2013.723253.

Grillo, Ralph, and Valentina Mazzucato. 2008. "Africa<>Europe: A Double Engagement." Journal of Ethnic and Migration Studies 34 (2): 175-198. DOI: $10.1080 / 13691830701823830$.

Katholieke Universiteit Leuven. 2017. Regulations on Education and Examinations 2017-2018. April 25. Accessed October 05, 2017. https://www.kuleuven.be/education/regulations/2017/\#f2387a33-f2c5-4de48777-ea6209cb31a0.

Katholieke Universiteit Leuven, interview by the first author. 2018. Secondary data on Cameroonian students (February 01). 
King, Russell, and Parvati Raghuram. 2013. "International Student Migration: Mapping the Field and New Research Agendas." Population, Space and Place 19 (2): 127-137. DOI: 10.1002/psp.1746.

Le Espiritu, Yen. 1994. "The intersection of race, ethnicity, and class: The multiple identities of second-generation Filipinos." Identities: Global Studies in Culture and Power 1 (2-3): 249-273. doi:10.1080/1070289X.1994.9962507.

Leung, Maggi W. H. 2017. "Social Mobility vis academic mobility: reconfigurations in class and gender identities among Asian scholars in the global north." Journal of Ethnic and Migration Studies. DOI: 10.1080/1369183X.2017.1314595.

Lucas, Rosemary, and Lucas Lammont. 1998. "Combining Work and Study: an empirical study of full-time students in school, college and university." Journal of Education and Work 11 (1): 41-56. DOI: 10.1080/1363908980110103.

Mazzucato, Valentina. 2011. "Reverse Remittances in the Migration-Development Nexus: Two-Way Flows between Ghana and the Netherlands." Population, Space and Place 17 (5): 454-468. doi:10.1002/psp.646.

Mazzucato, Valentina. 2009. "Informal Insurance Arrangements in Ghanian Migrants' transnational networks: The Role of Reverse Remittance and Geographic Proximity." World Development 36 (6): 1105-1115. doi:10.1016/j.worlddev.2008.11.001.

Mbaku, John Mukum. 2005. Culture and Customs of Cameroon. Westport, Conn.: Greenwood Press. 
Migration Policy Group. 2012. "Mobile Talent? The Staying Intentions of International Students in Five EU Countries." Accessed Febuary 2017. Migration Policy Group, 2012. Mobile Talent? The Staying Intentions of International Students in Five EU. https://www.stiftungmercator.de/media/downloads/3_Publikationen/SVR_Sykes_Chaoimh_Study_ Mobile_Talent_April_2012.

Moreau, Marie-Pierre, and Carole Leathwood. 2006. "Balancing paid work and studies:(-class) students in higher education." Studies in Higher Education 31 (1): 23-42. DOI: 10.1080/03075070500340135.

Neilson, Brett. 2009. "The World Seen from a Taxi : Students-Migrants in the Global Multiplication of Labour." Subjectivity 29 (1): 425-444. doi:10.1057/sub.2009.23.

Ngalim, B Valentine. 2014. "A conflict of colonial cultures in the educational subsystems in Africa: celebrating fifty years of political and not educational sovereignty in Cameroon." European Scientific Journal 1: 1857-7881.

Nyamnjoh, Francis. 2011. "Cameroonian bushfalling : negotiation of identity and belonging in fiction and Ethnography." American Ethnologist 38 (4): 701-713. doi:10.1111/j.1548-1425.2011.01331.x.

OECD. 2008. Jobs for immigrants: Labour market integration in Belgium, France, the Netherlands and Portugal. Vol. 2. Paris: OECD Publishing.

OECD. 2014. "Indicator C4: Who studies and where?" Education at a Glance 2014: OECD Indicators. Paris. doi.org/10.1787/888933118656. 
Olwig, Karen Fog, and Karen Valentin. 2015. "Mobility, education and life trajectories: new and old migratory pathways." Identities 22 (3): 247-257. DOI: 10.1080/1070289X.2014.939191.

Pelican, Michaela. 2013. "International Migration: Virtue or Vice? Perspectives from Camerooon." Journal of Ethnic and Migration Studies 39 (2): 237-258. doi:DOI: 10.1080/1369183X.2013.723256.

Pham, Lien, and David Saltmarsh. 2013. "International students' identities in a globalized world: Narratives from Vietnam." Journal of Research in International Education 12 (2): 129-141. DOI: 10.1177/1475240913481171.

Prothmann, Sebastian. 2017. "Migration, masculinity and social class: Insights from Pikine, Senegal." International Migration . doi:10.1111/imig.12385.

Raghuram, Parvati. 2013. "Theorising the Spaces of Student Migration." Population, Space and Place 19 (2): 138-154. doi:DOI: 10.1002/psp.1747.

Robertson, Shanthi. 2011. "Cash cows, backdoor migrants, or activist citizens? International students, citizenship, and rights in Australia." Ethnic and Racial Studies 34 (12): 2192-2211. DOI: 10.1080/01419870.2011.558590.

Salazar, B. Noel. 2011. "The Power of Imagination in Transnational Mobilities." Identities 18 (6): 576-598. DOI: 10.1080/1070289X.2011.672859.

Stryker, Sheldon, and J. Peter Burke. 2000. "The Past, Present, and Future of an Identity Theory." Social Psychology Quarterly 63 (4): 248-297. http://www.jstor.org/stable/2695840. 
Valentin, Karen. 2015. "Transnational education and the remaking of social identity: Nepalese student migration to Denmark." Identities 22 (3): 318-332. DOI: 10.1080/1070289X.2014.939186.

Whitehouse, Bruce. 2011. "Enterprising Strangers: Social Capital and Social Liability Among African Migrant Traders." International Journal of Social Inquiry 93 (111): 93-111.

Wilken, Lisanne, and Mette Ginnerskov Dahlberg. 2017. "Between international student mobility and work migration: experiences of students from EU's newer member states in Denmark." Journal of Ethnic and Migration Studies 43 (8): F 13471361. DOI: 10.1080/1369183X.2017.1300330.

Winn, Sandra. 2002. "Student Motivation: A socio-economic perspective." Studies in Higher Education 27 (4): 445-457. DOI:10.1080/0307507022000011552. 